\title{
Ly9 (CD229) cell-surface receptor is crucial for the development of spontaneous autoantibody production to nuclear antigens
}

\author{
Jose de Salort ${ }^{1}$, Marta Cuenca ${ }^{1}$, Cox Terhorst ${ }^{2}$, Pablo Engel ${ }^{1}$ and Xavier Romero ${ }^{1,3}$ * \\ 1 Immunology Unit, Department of Cell Biology, Immunology and Neurosciences, Medical School, University of Barcelona, Barcelona, Spain \\ 2 Division of Immunology, Beth Israel Deaconess Medical Center, Harvard Medical School, Boston, MA, USA \\ ${ }^{3}$ Institut D'Investigacions Biomèdiques August Pi i Sunyer (IDIBAPS), Barcelona, Spain
}

\section{Edited by:}

Masaaki Murakami, Osaka University, Japan

\section{Reviewed by:}

Yasunobu Arima, Osaka University, Japan

Stefano Volpi, Harvard Medical School, USA

\section{${ }^{*}$ Correspondence:}

Xavier Romero, Immunology Unit, Department of Cell Biology, Immunology and Neurosciences, Medical School, University of Barcelona, Casanova 143, Barcelona 08036, Spain

e-mail: jaromero@clinic.ub.es
The Signaling Lymphocyte Activation Molecule Family (SLAMF) genes, which encode cell-surface receptors that modulate innate and adaptive immune responses, lay within a genomic region of human and mouse chromosome 1 that confers a predisposition for the development of systemic lupus erythematosus (SLE). Herein, we demonstrate that the SLAMF member Ly9 arises as a novel receptor contributing to the reinforcement of tolerance. Specifically, Ly9-deficient mice spontaneously developed features of systemic autoimmunity such as the production of anti-nuclear antibodies (ANA), -dsDNA, and -nucleosome autoantibodies, independently of genetic background [(B6.129) or (BALB/C.129)]. In aged (10- to 12-month-old) $L y 9^{-1-}$ mice key cell subsets implicated in autoimmunity were expanded, e.g., T follicular helper (Tfh) as well as germinal center (GC) B cells. More importantly, in vitro functional experiments showed that Ly9 acts as an inhibitory receptor of IFN- $\gamma$ producing $\mathrm{CD} 4^{+} \mathrm{T}$ cells. Taken together, our findings reveal that the Ly9 receptor triggers cell intrinsic safeguarding mechanisms to prevent a breach of tolerance, emerging as a new non-redundant inhibitory cell-surface receptor capable of disabling autoantibody responses.

Keywords: SLAMF, Ly9 (CD229, SLAMF3), anti-DNA autoantibodies, disease susceptibility, systemic lupus erythematosus, murine Lupus

\section{INTRODUCTION}

Systemic lupus erythematosus (SLE) is a multisystem autoimmune disease characterized by major immunological stigmata, the production of antibodies against own cellular nuclear components. The mechanisms underlying SLE are complex and include genetic, epigenetic, environmental, hormonal, and immunoregulatory factors. Furthermore, multiple pathogenic pathways likely contribute to end-organ damage in this heterogeneous disease (13). Elucidation of these pathways, as well as the identification of new molecular disease markers and targets that account for the pathogenesis of lupus, are crucial to improve currently available therapeutic approaches.

Genetic predisposition is a central factor to the development of SLE $(4,5)$. Both Genome Wide Association studies (GWAS) and the in depth analyses of genetically altered and congenic mice have provided insights into the genetic control of lupus. For instance, mouse strains bearing either a NZW- or 129-derived genomic segment that is embedded in chromosome 1 of B6 mice, develop a lupus-like disease due to the epistatic interactions between the 129-derived genes and B6 genes (6). Analysis of congenic NZW $\times$ B6 mice identified the Sle1 region of chromosome 1 and its subregions Slela, -b, and -c, as key elements involved in breaching B- and T-cell tolerance to chromatin, an essential early step leading to full-blown onset of the disease. Remarkably, multiple gene-wide linkage scans in SLE families have also identified a syngenic lupus susceptibility locus (region 1q23) in human chromosome $1(7,8)$.

Precise mapping of the Sle1 region identified a gene interval of $0.9 \mathrm{Mb}$, termed Sle1b, as the most potent segment involved in the generation of autoantibodies. Interestingly, this segment includes seven signaling lymphocyte activation molecule family (SLAMF) cell-surface receptor genes (9). The proteins encoded by these genes are the best suited candidates for controlling signaling pathways in Sle1 tolerance due to their extensive polymorphic nature and isoform diversity, coupled with their ability to modulate innate and adaptive immunity $(10,11)$. The SLAMF receptors (SLAMF1-9) are involved in the functional regulation of several immune cell types, including helper and cytotoxic $\mathrm{T}$ lymphocytes, NK cells, and macrophages (12-15). These receptors mediate adhesion and regulate cognate T-cell-B-cell interactions, which elicit signal transduction by recruiting SLAM-associated protein (SAP). Importantly, SAP deficiency selectively impairs the ability of $\mathrm{CD} 4^{+} \mathrm{T}$ cells to stably interact with cognate $\mathrm{B}$ cells, avoiding differentiation toward $\mathrm{T}$ follicular helper cells (Tfh), and the generation of T-dependent B-cell responses (16-18). Consistent with this role, the absence of SAP mitigates autoimmunity in various mouse models of lupus by disrupting the generation of germinal centers (GC) $(19,20)$. Increasing evidence suggests that a defective response to self-antigens in the periphery can constitute a relevant pathogenic event. More specifically, autoantibodies 
detected in lupus patients and lupus-prone mice had suffered isotype switching and somatic hypermutation, which facilitated the binding to self-antigens with high affinity, all indicating the involvement of GC pathways in this disease $(21,22)$. This, therefore, provides a rational for determining not only the exact role played by SLAMF receptors as key drivers of Tfh and GC formation, but also their potential as appealing therapeutic targets for autoantibody-mediated diseases.

While recent reports have identified Slamf6 (Ly108) receptor and its isoforms and Slamf2 (2B4) as contributing to the role played by Sle1b in tolerance (23-25), the involvement of other SLAMF members cannot be excluded. Of particular interest is the Ly9 (CD229, Slamf3) molecule, since a comparative analysis between B6 and the autoimmune congenic strain B6.Sle1b revealed significant differences in its isoforms usage, as well as in the extent of polymorphisms and expression levels (9), with the evidence indicating the possible participation of Ly9 in B6.Sle1b autoimmunity. Briefly, Ly9 expression is restricted to hematopoietic cells, including B and T lymphocytes (26). As has been shown in other SLAMF members, Ly9 functions as a homophilic adhesion receptor and its cytoplasmic tail contains two copies of the conserved tyrosine-based switch motif (ITSM), which is a docking site for the adapter molecules SAP and EAT-2 $(27,28)$. Ly9-deficient mice with a mixed $129 \times$ B6 background exhibited no major T-cell developmental abnormalities and only very mild defects in T-cell responses (29). Recent findings demonstrate the role of Ly9 as a unique inhibitory cell-surface receptor regulating the size of the thymic innate $\mathrm{CD} 8^{+} \mathrm{T}$-cell pool and the development of invariant Natural Killer T ( $i$ NKT) cells (30). Nonetheless, the functional role of Ly9 in lupus pathogenesis remains unknown. Here, we use Ly9-deficient mice, which were generated with 129-derived ES cells and then backcrossed onto B6 or BALB/c backgrounds, in order to determine the role of the Ly9 receptor in autoantibody development.

\section{MATERIALS AND METHODS}

\section{MICE}

Ly9 $9^{-/-}$mice $(129 \times$ B6), generously provided by Dr. McKean (29), were backcrossed onto BALB/c background for 12 generations to generate the $L y 9^{-/-}(B A L B / c .129)$ strain and onto C57BL/6 (B6) background for 12 generations to generate the $L y 9^{-/-}(B 6.129)$ strain. Eight-week-old BALB/c and B6 wild-type mice were purchased from Charles River Laboratories (Saint-Aubin-lès-Elbeuf, France). All mice strains were maintained under specific pathogenfree (SPF) conditions for up to 12 months. Serum samples were collected from the tail vein at 3-, 6-, 9-, and 12-months of age. At 12 months, mice were euthanized, a peritoneal lavage was carried out and kidneys, bone marrow, spleen, thymus, and sera were harvested. Experiments were conducted in compliance with institutional guidelines as well as with national laws and policies.

\section{ANTI-NUCLEAR ANTIBODIES ANALYSIS}

Anti-nuclear antibodies (ANA) titers were determined by indirect immunofluorescence using permeabilized Hep-2 cells. Serum samples were progressively diluted and incubated for $1 \mathrm{~h}$ at room temperature on Hep-2 cells followed by Texas Red-conjugated anti-mouse IgG (Jackson Laboratory, Bar Harbor). After washing, the nucleus was stained with $4^{\prime}, 6$-diamidino-2-phenylindole (DAPI). Analysis was performed by fluorescence detection using a Nikon Eclipse fluorescent microscope (Nikon, Tokyo).

\section{ANTI-DOUBLE-STRANDED DNA AND ANTI-CHROMATIN DETECTION}

ELISA assays were performed to quantify levels of anti-doublestranded DNA (anti-dsDNA) and anti-chromatin antibodies in sera of mice. For anti-dsDNA detection, an ELISA was carried out using heat-denatured calf thymus DNA (Sigma Chemical Co., St Louis, MO, USA). dsDNA was coated onto 96-well plates (Corning Costar, Corning, NY, USA) at $10 \mu \mathrm{g} / \mathrm{ml}$. Purified antibody anti-dsDNA (Clone HpS22, Immunotools, Friesoythe, Germany), used as standard, was serially diluted. Standards and test serums (dilution 1:100) were incubated on plates for $1 \mathrm{~h}$ at room temperature. After extensive washing, autoantibodies were detected using a HRP-conjugated anti-mouse IgG (Sigma-Aldrich) and developed with OPD substrate (Sigma-Aldrich).

Anti-chromatin autoantibodies were detected using nucleosome antigen (Arotec Diagnostics Limited, Wellington, New Zealand). The nucleosome antigen was coated on 96-well plates at $3 \mu \mathrm{g} / \mathrm{ml}$. Serums were diluted 1:100 and incubated for $1 \mathrm{~h}$ at room temperature. Autoantibodies against nucleosome were detected using a HRP-conjugated anti-mouse IgG and developed with substrate. All samples were handled simultaneously under the same experimental conditions and results are expressed as OD values.

\section{IgG ISOTYPE DETECTION}

Basal serum IgG isotypes were determined by ELISA using purified goat anti-mouse IgG (Sigma-Aldrich) coated 96-well plates. 1:100 diluted mouse serums were incubated for $1 \mathrm{~h}$ at room temperature. After extensive washing, IgG isotypes were detected using biotin-conjugated anti-mouse $\operatorname{IgG}_{1}, \operatorname{IgG}_{2 \mathrm{a}}, \operatorname{IgG}_{2 \mathrm{~b}}$, and IgG $\mathrm{IJack}_{3}$ son Laboratory). All samples were handled simultaneously under the same experimental conditions and results are expressed as OD values.

\section{FLOW CYTOMETRY}

Single-cell suspensions were incubated with $20 \%$ heat-inactivated rabbit serum before being stained on ice with fluorophorelabeled antibodies against surface molecules using standard methods. Data was acquired using a FACSCanto II (BD Pharmingen, San Jose, CA, USA) flow cytometer and analyzed with either FACSDiva ${ }^{\mathrm{TM}}$ (BD Pharmingen) or FlowJo software (Tree Star, San Carlos, CA, USA). The following anti-mouse mAbs were obtained from BD Pharmingen: CD4-FITC, CD11b-PE, CD21-FITC, CD23-FITC, CD24-FITC, CD43-FITC, CD44-FITC, CD62L-FITC, CD69-FITC, CD154-PE, c-Kit-PE, Ter-119-PE, IgM-biotinylated, and CXCR5-biotinylated. The mAbs CD8FITC, CD11b-FITC, CD25-PE, CD25-FITC, IgM-FITC, B220FITC, as well as the isotype-matched control Abs, were acquired from ImmunoTools (Friesoythe, Germany). The following mAbs were obtained from BioLegend (San Diego, CA, USA): CD3FITC, CD4-Pacific Blue, CD8-PE-Cy5, PD1-PE, PD1-PE-Cy7, B220-Pacific Blue, CD41-FITC, and IgD-APC-Cy7. The mAbs CD3-APC, CD5 PE-Cy7, CD229-APC, Sca-1-APC, and GL-7FITC were purchased from eBioscience (San Diego, CA, USA). Anti-mouse CD138-APC was obtained from R\&D Biosystems 
(R\&D System, Wiesbaden, Germany). R-PE labeled murine CD1d tetramer pre-loaded with PBS57 (NIH Tetramer Core Facility, Atlanta, GA, USA) was used to detect $i$ NKT cells according to the manufacturer's instructions. Streptavidin PERCP-Cy5.5 was obtained from BD Pharmingen and streptavidin PE-Cy5 from eBioscience. For intracellular staining with IFN- $\gamma$ and IL-17, cells were made permeable with an intracellular staining buffer (eBioscience). Anti-IFN- $\gamma$-PE (Clone XMG1.2, BD Pharmingen) or anti-IFN- $\gamma$ FITC (XMG1.2; eBioscience), and anti-IL-17-APC (Clone TC11-18H10.1, BioLegend) were used for intracytoplasmic staining.

\section{KIDNEY HISTOLOGY AND URINE ASSAYS}

Kidneys were fixed with $4 \%$ formalin (PBS), dehydrated, and embedded in paraffin. All sections were counterstained with Gill's hematoxylin (Panreac, Spain), dehydrated with graded alcohol and xylene, and mounted with DPX (VWR International, Radnor, PA, USA). To evaluate IgG-immunocomplex deposits on kidneys, snap-frozen spleens in OCT media (Sakura Finetek Europe B.V., The Netherlands) were cryosectioned $(5 \mu \mathrm{m})$, blocked with $6 \%$ FCS in PBS, and stained with alexa 488-conjugated anti-mouse IgG (Life Technologies Corporation, Invitrogen, Paisley, UK). Images were analyzed using a Nikon Optiphot-2 microscope (Nikon) and acquired with a high-definition color camera (Nikon).

Freshly voided urine samples were tested for proteinuria using Albustix (Siemens Healthcare Diagnostics Inc. Tarrytown, NY, USA).

\section{IN VITRO CELL ACTIVATION}

Splenic lymphocytes were activated with plate-bound anti-CD3 $(2 \mu \mathrm{g} / \mathrm{ml})(145-2 \mathrm{C} 11$; BD Pharmingen $)$ combined with purified soluble anti-CD28 (1 $\mu \mathrm{g} / \mathrm{ml})$ (37.51; BD Pharmingen). Splenocytes $(100,000$ cells/well) were cultured in RPMI 1640 medium supplemented with $10 \% \mathrm{FBS}, 100 \mathrm{IU} / \mathrm{ml}$ of penicillin, $100 \mu \mathrm{g} / \mathrm{ml}$ of streptomycin, and $2.5 \mu \mathrm{M}$ of $\beta$-mercaptoethanol in a 96-well plate and activated. Supernatants were collected after $72 \mathrm{~h}$ of incubation and IFN- $\gamma$ levels were measured by ELISA. Additionally, after $24 \mathrm{~h}$ of activation, cells were collected and the percentages of activation markers (CD25, CD40L) were analyzed by flow cytometry. Th17 cell polarization was carried out according to BioLegend's protocol. Briefly, single splenocyte suspensions were activated with $2 \mu \mathrm{g} / \mathrm{ml}$ of plate-bound anti-CD3 (clone 145-11; BioLegend), anti-CD28 (5 $\mu \mathrm{g} / \mathrm{ml}$; clone 37.51, BD Pharmingen), TGF$\beta 1(1 \mathrm{ng} / \mathrm{ml}$, BioLegend), anti-IFN- $\gamma(10 \mu \mathrm{g} / \mathrm{ml}$; clone XMG1.2, BD Pharmingen), anti-IL-4 (10 $\mu \mathrm{g} / \mathrm{ml}$; clone 11B11; BioLegend), IL-6 (50 ng/ml, Immunotools), and IL-23 (5 ng/ml, BioLegend) over 3 days. Cells were then stimulated for $4-5 \mathrm{~h}$ with phorbol myristate acetate (PMA; $50 \mathrm{ng} / \mathrm{ml}$; Sigma-Aldrich) and ionomycin $(750 \mathrm{ng} / \mathrm{ml}$; Sigma-Aldrich) in the presence of GolgiStop at 1:1500 (Pharmingen).

\section{MEASUREMENT OF CYTOKINES}

The amounts of IFN- $\gamma$ in sera or in cell-culture supernatants were evaluated with commercially available ELISA kits (R\&D Systems). Intracellular analysis of cytokines produced by $\mathrm{CD} 4^{+}$and $\mathrm{CD} 8^{+}$ $\mathrm{T}$ cells, and $i$ NKT cells was carried out by FACS analysis.

Spleen $\mathrm{CD}^{+}{ }^{+} \mathrm{T}$ cells were isolated by using MACS CD4 ${ }^{+} \mathrm{T}$ cell Isolation Kit II (Miltenyi Biotec), following manufacturer's protocol. Cells were stimulated for $4-5 \mathrm{~h}$ with PMA $(50 \mathrm{ng} / \mathrm{ml})$, ionomycin $(750 \mathrm{ng} / \mathrm{ml})$, and GolgiStop at 1:1500. APC-conjugated anti-CD3 (eBioscience), pacific blue-conjugated anti-CD4 (BioLegend), PE-Cy7-conjugated anti-CD8 (BioLegend), pacific blueconjugated anti-B220 (BioLegend), and PE-conjugated tetramerPBS57 (NIH) were used for flow cytometry staining. Cells were then fixed and permeabilized with Foxp3 Staining Buffer (eBioscience) before intracellular staining with alexa fluor 647-conjugated anti-IL-17 (clone TC11-18H10.1; BioLegend), phycoerythrin-conjugated anti-IFN- $\gamma$ (XMG1.2; BD Pharmingen) or FITC-conjugated anti-IFN- $\gamma$ (XMG1.2; eBioscience), IL-4 PE-Cy7 (11B11; BD Pharmingen).

\section{IN VITRO PROLIFERATION AND VIABILITY ASSAYS}

Splenocytes were resuspended in PBS with 5\% FCS $\left(10^{6}\right.$ cells $\left./ \mathrm{mL}\right)$, and stained with CFSE (Invitrogen) ( $1 \mu \mathrm{L} \mathrm{CFSE} \mathrm{for} \mathrm{each} 10^{6}$ cells), during $5 \mathrm{~min}$ at room temperature. Then cells were washed with cold PBS with 5\% FCS and with cold PBS. After the second wash, lymphocytes were resuspended in RPMI media (10\% FCS, and $2.5 \mu \mathrm{M} \beta$-mercaptoethanol). Cells were stimulated with $10 \mu \mathrm{g} / \mathrm{mL}$ $\mathrm{F}\left(\mathrm{ab}^{\prime}\right)_{2}$ anti-mouse IgM (Jackson ImmunoResearch), or complete media as a negative control.

In order to measure viability, lymphocytes were stained with fluorochrome-labeled antibodies against surface antigens using standard methods. Cells were washed twice in azide-free and serum/protein-free PBS, and stained with Live/Dead Fixable far Red (Invitrogen) following manufacturer's protocol. Then lymphocytes were stained with eFluor 450-conjugated Annexin V eBioscience during $15 \mathrm{~min}$ at room temperature, and washed with RPMI media. Proliferation and viability were assessed $72 \mathrm{~h}$ later.

\section{STATISTICS}

Mann-Whitney tests were used to calculate $p$ values for all numeric data.

\section{RESULTS}

\section{Ly9-DEFICIENT MICE DEVELOP SPONTANEOUS AUTOIMMUNITY}

To assess the role of Ly9 in humoral autoimmune responses, Ly9deficient mice were generated by mutated 129-derived ES cells (29) and backcrossed with B6 (C57BL/6) or BALB/c mice for 12 generations. First, we analyzed the presence of ANA in sera of 3, 6, 9, and 12 months old $L y 9^{-/-}$(B6.129) mice by immunofluorescence staining of Hep- 2 cells. As shown in Figures 1A,B, an ageassociated increase in ANA titers was detected in $\mathrm{Ly} \mathrm{9}^{-/-}$(B6.129) mice that was significantly higher than those of their age-matched $L y 9^{+/+}$(wild-type; wt) counterparts. The differences in ANA serum levels between wt and $L y 9^{-/-}$mice were statistically significant as early as 3 months of age. At 12 months of age, $80 \%$ of the serum samples from $L y 9^{-/-}$(B6.129) showed ANA titers $\geq 1: 4096$. In contrast, $100 \%$ of the serum titers from their wt counterparts measured $\leq 1: 512$. Further analysis demonstrated that by age 12 months $L y 9^{-/-}$(B6.129) mice displayed significant increases in their circulating levels of anti-double-stranded (ds) DNA and anti-nucleosome IgG antibodies in comparison to their wt counterparts (Figures 1C,D).

In order to further dissect the role of Ly9 in the humoral autoimmune response, excluding any effects stemming from 


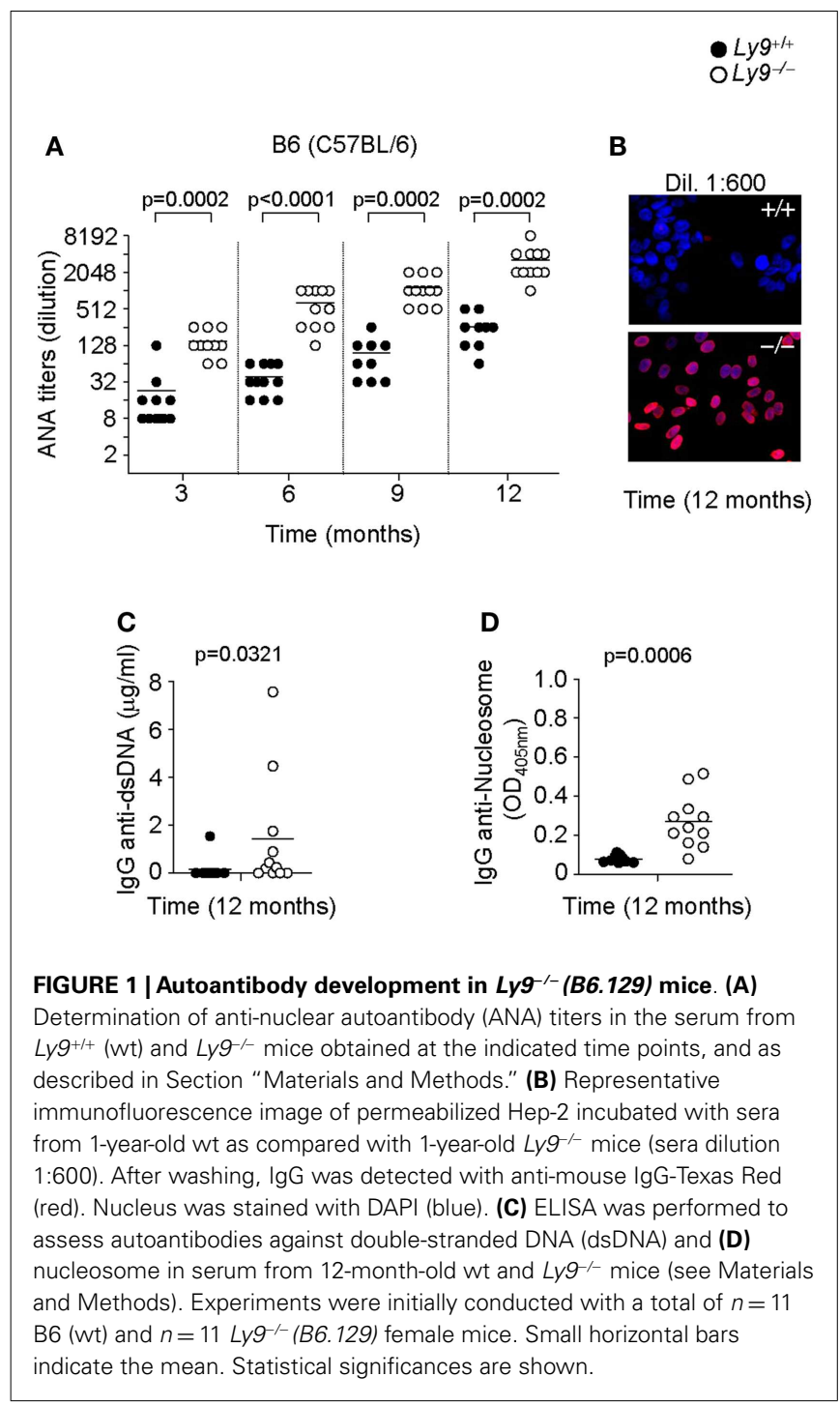

epistatic interactions, we determined autoantibodies in the serum of $L y 9^{-/-}(B A L B / c .129)$ mice. Once again, an age-associated increase in ANA titers was also detected in $L y 9^{-/-}$(BALB/C.129) mice that was significantly higher than those of their agematched wt counterparts. As was observed in the B6 background mice, the differences in ANA serum levels between wt and $L y 9^{-/-}(B A L B / C .129)$ mice were statistically significant as early as 3 months of age, reaching its highest level at age 12 months when $91.6 \%$ of $L y 9^{-/-}(B A L B / c .129)$ mice presented ANA titers $\geq 1: 256$ compared with $72.7 \%$ of their wt counterparts whose titers measured $\leq 1: 64$ (Figures 2A,B). Notably, ANA titers in $L y 9^{-/-}(B 6.129)$ mice were always higher than those of $L y 9^{-/-}(B A L B / C .129)$ at the evaluated time points, most likely due to the additional effect of the epistatic interactions, which induced spontaneous loss of immune tolerance to nuclear antigens (25). Comparable levels of antidsDNA and anti-nucleosome were detected on Ly9-deficient mice from both genetic backgrounds (Figures 2C,D and Figures 1C,D), although $L y 9^{-/-}($B6.129) mice displayed much

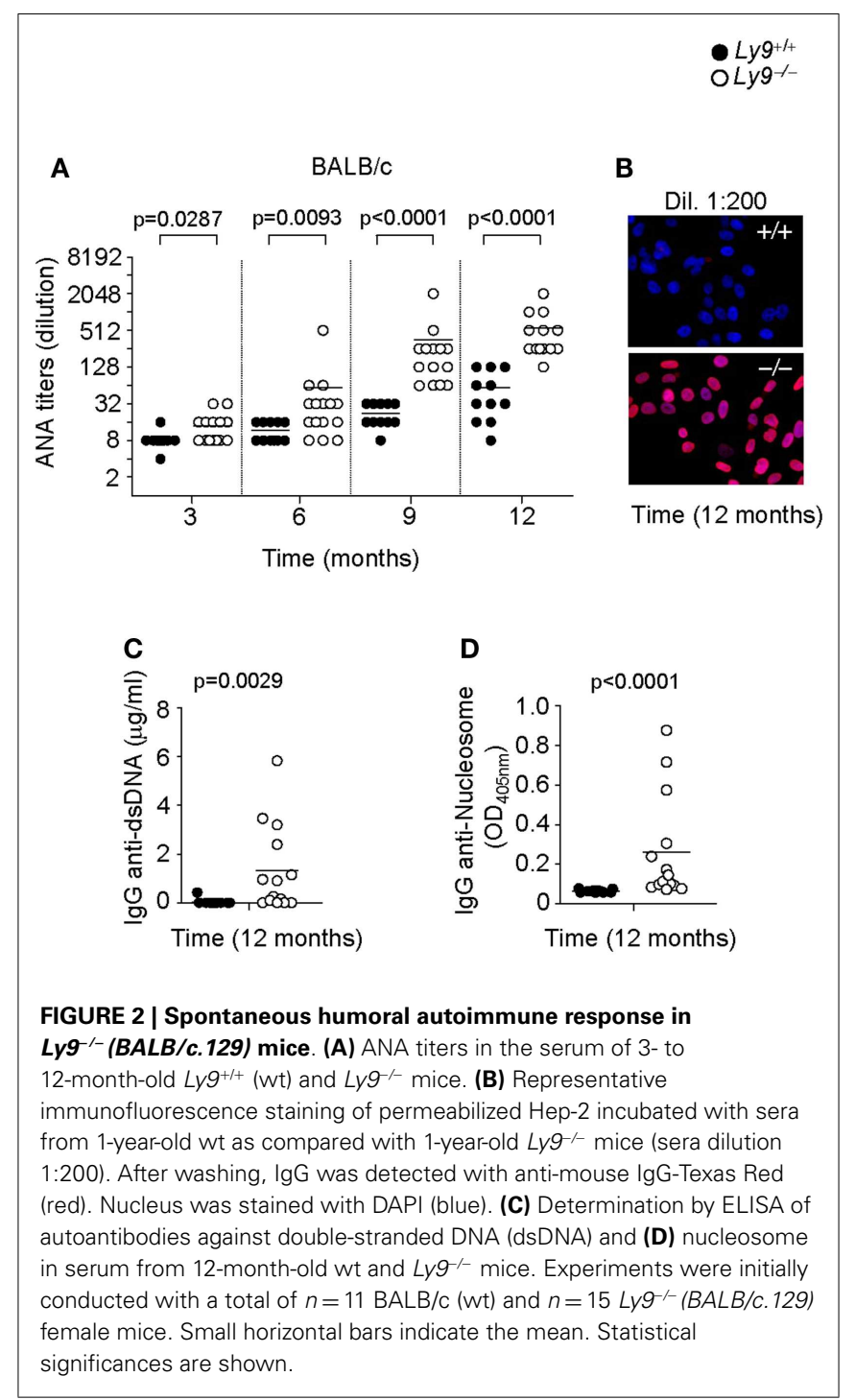

higher ANA titers. This likely reflects the presence of preferential nuclear antigen recognition based on genetic background, which has been also observed in other lupus models (31).

Ly9-deficient mice exhibited a significant increase in IgG2b (Figure 3A) as well as higher ratios of IgG2a, 2b, and IgG3 isotypes vs. IgG1 than wt mice. Due to the high titers of autoantibodies observed on aged Ly9-deficient mice sera, we further investigated the presence of alterations in these animals' renal physiology and functionality. Twelve-month-old $L y 9^{-/-}$(BALB/c.129) mice did not exhibit proteinuria (Figure 3B) or differences in their glomeruli morphology compared to their wt counterparts. Although we observed a mild increase in IgG-immunocomplex deposits in Ly9-deficient mice (Figure 3C), this initial trait prior to any sign of glomerulonephritis did not trigger a renal pathology.

In summary, our findings reveal that the absence of the Ly9 receptor per se initiates the progressive development of autoantibodies, independently of any epistatic interactions. 


\section{- $L y 9^{+/+}$ \\ OLy $9^{-1-}$}

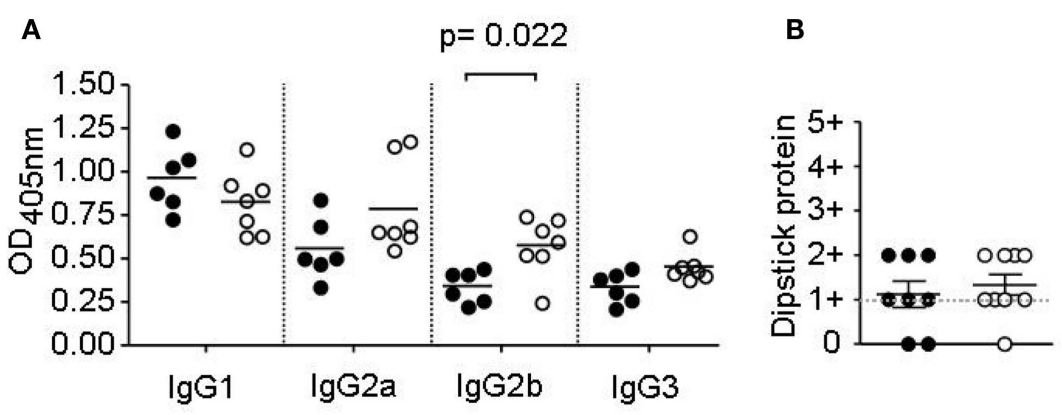

C

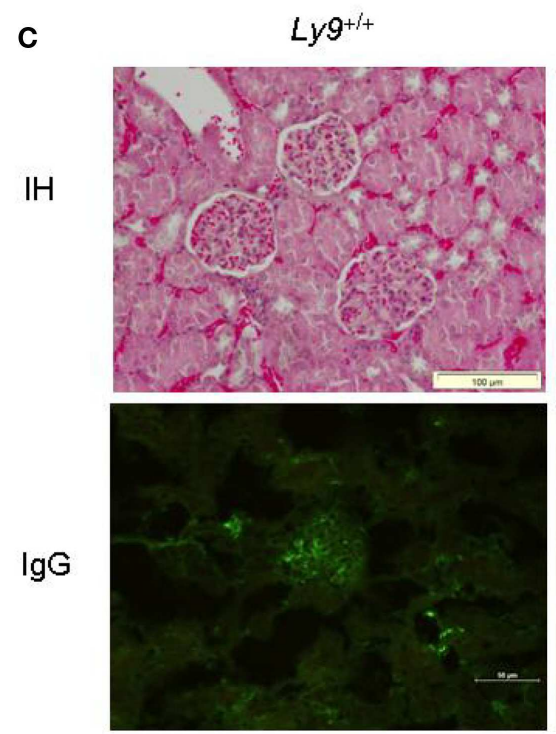

$L y 9^{-1-}$
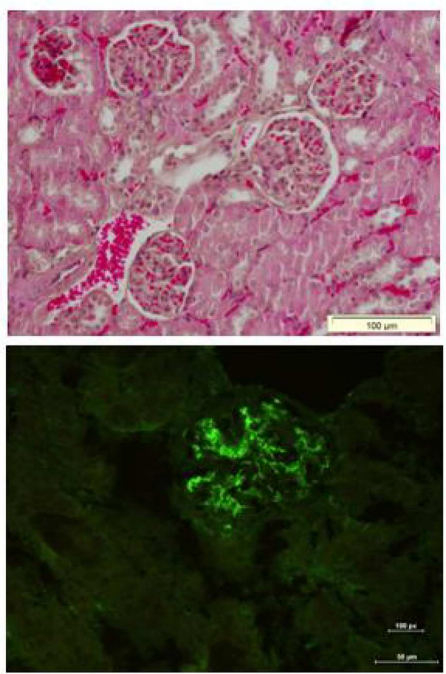

FIGURE 3 | One-year-old $L y 9^{-/-}$(BALB/c. 129) mice showed a skewed IgG isotype and no renal pathology. (A) Indicated $\lg G$ isotypes were analyzed in sera from 12-month-old $L y 9^{-1}$ (BALB/C. 129) and wt mice. (B) Protein was measured with a colorimetric dipstick in fresh urine samples from 12-month-old mice. (C) Representative immunohistology (IH) image (Gill's hematoxylin) of paraffin-embedded kidney sections (upper panels) and IgG-immunocomplex image detected by immunofluorescence (bottom panels) of cryopreserved kidney sections from 12-month-old wt $(n=4)$ and Ly9 $9^{-1-}(n=4)$ mice. Horizontal bars represent the mean level. SEM and statistical significance are shown.

\section{$\angle y g^{-/-}$AGED MICE EXHIBITED SPLENOMEGALY AND ALTERED KEY CELL SUBSETS RELATED TO SELF-TOLERANCE}

The role of Ly9 as an inhibitor molecule in the development of spontaneous autoimmunity, excluding any effects dictated by epistatic interactions, is further supported by the observation that 12 -month-old $L y 9^{-/-}(B A L B / c .129)$ mice exhibited splenomegaly, which is a feature often present in SLE-prone mice $(32,33)$. The mean and SEM of spleen weight in wt $(n=7)$ and $L y 9^{-/}(B A L B / c .129)$ mice $(n=11)$ were $95.53 \pm 3.40$ and $147.7 \pm 10.36 \mathrm{mg}$, respectively $(p=0.0021)$. Consistently, an increase of $75.8 \%$ in $L y 9^{-/-}(B A L B / c .129)$ spleen cell numbers, compared with wt spleens, was observed (Figures 4A,B).

A deeper analysis of cell subsets by flow cytometry demonstrated altered B- and T-cell peripheral homeostasis in
Ly9-deficient mice. We first inspected the B-cell signature of the disease in 12-month-old $\mathrm{Lyg}^{-1-}(B A L B / C .129)$ mice (Table 1). Notably, the most significant difference was found in GC B cells, with a percentage of $0.64 \pm 0.19$ in $w t$ and $1.28 \pm 0.30$ in $L y 9$ deficient mice $(p=0.0004)$, which was also evident due the striking expansion of GC cell numbers (Figure 4C and Table 1). Although a major percentage of GC was observed in $L y 9$-deficient mice, only a slight decrease in the percentage of Follicular B cells was detected: $88.39 \pm 3.15\left(L y 9^{+/+}\right)$and $78.01 \pm 7.25\left(L y 9^{-/-}\right)$, which is indicative of follicular B-cell areas with a major proportion of GC B cells. Transitional 1 (T1) B cells in wt and $L y 9^{-/-}(B A L B / c .129)$ mice showed percentages of $4.48 \pm 1.08$ and $9.47 \pm 3.12$, respectively. Marginal zone (MZ) B cells from $L y 9$ deficient mice also showed increased percentages: $4.54 \pm 1.78$ 

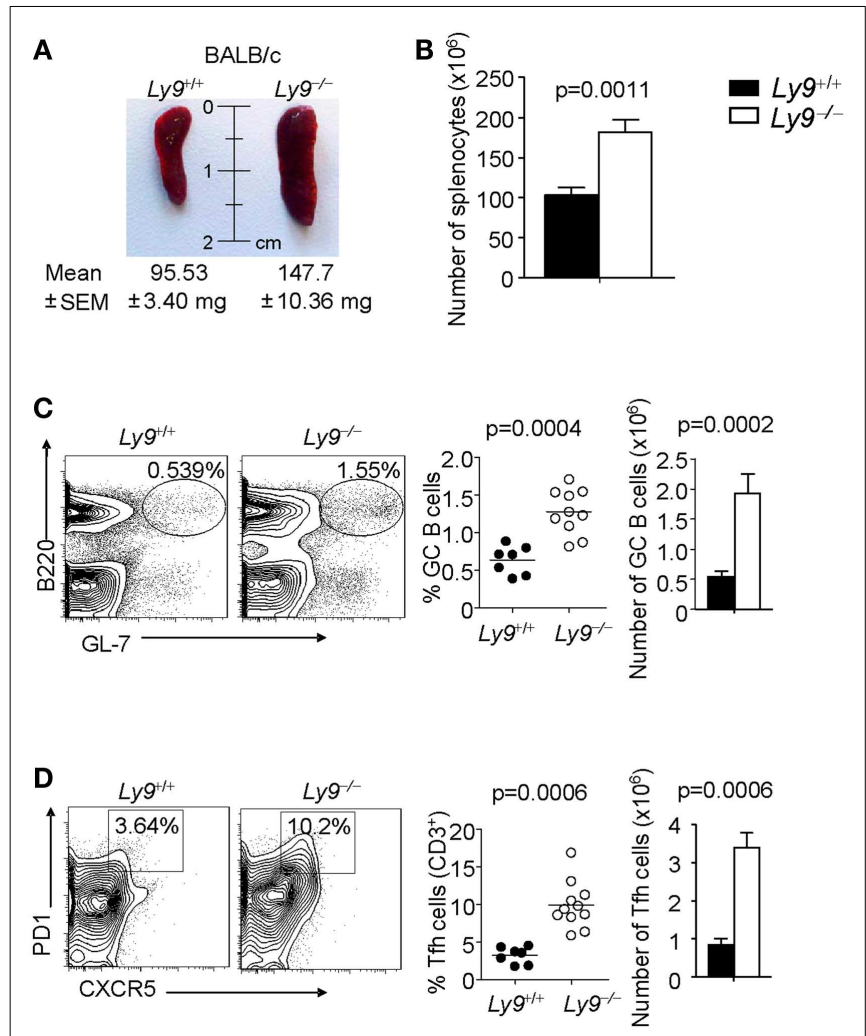

FIGURE 4 | $L y 9$ ablation alters key peripheral $B$ and T subsets implicated in autoimmunity. (A) Representative picture of spleens from 12-month-old wt $(n=7)$ and $\angle y 9^{-/}(B A L B / C$. 129) $(n=11)$; weight mean and SEM are shown. (B) Spleen cellularity was determined. (C) Splenocytes were stained with anti-B220 and anti-GL7 mAbs to calculate the percentages and total cell numbers in the germinal center (GC) B cell compartment, (D) or stained with anti-CD3, anti-CD4, anti-PD1, and anti-CXCR5 to analyze Tfh cells. Horizontal bars represent the mean level. SEM and statistical significances are shown.

$\left(L y 9^{+/+}\right)$and $8.70 \pm 2.97\left(L y 9^{-/-}\right)$(Table 1). Thus, the previously mentioned B-cell subsets, most of them involved in autoimmune diseases $(34,35)$, showed a near twofold percentage increase in $L y 9^{-/-}(B A L B / c .129)$ mice compared to their control counterparts.

No altered proportion was found in the studied peritoneal Bcell subsets from the 12-month-old mice (data not shown). Our data also revealed a slightly increased frequency in the occurrence of the most immature B-cell lineages, multipotent progenitor (MMP) and Pro-B cells in the bone marrow of Ly9-deficient mice (data not shown), which is a variation that has been observed in other lupus-prone mice (36).

In examining the T-cell signature of $L y 9$ deficiency-mediated autoimmunity, the most remarkable difference we observed was in Tfh cells, which showed a threefold percentage increase and cell number expansion (Figure 4D). Importantly, excessive Tfh-cell numbers have been linked to a positive-selection defect in GC, which would account for such differences in the autoantibody generation (21). As previously mentioned, $L y 9$-deficient mice also exhibited higher ratios of IgG2a,b and IgG3 isotypes vs. IgG1, suggesting that the peripheral tolerance checkpoint that controls GC and Tfh cells becomes altered by the absence of Ly9 molecule (Figure 3A). In the $L y 9$-deficient spleen, we found a slight increase in the ratios occurring between $\mathrm{CD} 4^{+}$and $\mathrm{CD} 8^{+} \mathrm{T}$ cells. We also observed an increase in effector $\mathrm{CD}^{+}$and $\mathrm{CD} 8^{+} \mathrm{T}$-cell subsets, although it was not significant. Interestingly, the $i \mathrm{NKT}$ cell pools in these animals were also enlarged: $3.53 \pm 1.23 \% \mathrm{wt}$ and $7.67 \pm 2.80 \% L y 9^{-/-}$mice (Table 1 ).

We conclude that $L y 9$ gene ablation in a BALB/c background results in the disturbance of $B$ and $T$ cell subsets involved in autoimmunity, with major differences occurring in both Tfh cells and GC B cells.

\section{Ly 9 RECEPTOR MODULATES IFN $-\gamma$ SECRETION BY CD4 ${ }^{+}$T CELLS}

To determine the lymphocyte subsets that facilitate the ignition of SLE-related pathology in the absence of $L y 9$, we searched for any altered peripheral cell populations in 8- to 12-week-old $L y 9^{-/-}(B A L B / c .129)$ mice. Slight differences were observed in the T-splenic compartment with a small increase in percentage of $\mathrm{CD}^{+}{ }^{+} \mathrm{T}$ and $i$ NKT. Notably, most of the alterations were displayed by B-cell subsets, with Transitional T1 B cells presenting the major difference (Table 2). A deeper examination of T1 and MZ B cells including IgM as a cell marker (T1:CD23 ${ }^{-} \mathrm{CD} 21^{-} \mathrm{IgM}^{+}, \mathrm{MZ}$ : $\mathrm{CD}_{23}{ }^{-} \mathrm{CD} 21^{+} \mathrm{IgM}^{+}$) (37) demonstrates that Ly9-deficient mice possessed approximately a threefold increase of $\mathrm{T} 1$ subset and also an expanded MZ B subset (Figure S1 in Supplementary Material). Based on these results, we conclude that $L y 9$-deficiency alters the development of B-cell subsets which may be involved in the generation of autoantibodies.

Abnormalities in BCR signaling could shape the splenic B-cell populations and predispose to autoimmune disease. Therefore, we assessed the proliferation and survival of splenic B cell from $L y 9^{-1-}$ mice after IgM stimulation. The proliferation and apoptotic responses of Ly9-deficient B cells were similar to those observed in the wt B cells, with the exception of a slight decrease in percentage of late apoptotic cells in the Ly9-deficient mice (Figure 5).

Since earlier studies have demonstrate the critical implication of SLAMF receptors in Th1/Th2/Th17 polarization $(14,26,38)$, we hypothesized that Ly9-deficient splenocytes in 8- to 12-weekold mice would foster an alteration in T-cell cytokine production prior to disease onset, thereby enabling autoantibody production at older ages. First, we asked whether the ablation of murine $L y 9$ could modulate IL- 17 secretion by $\mathrm{CD}^{+}{ }^{+} \mathrm{T}$ cells under Th 17 polarizing conditions, since earlier reports have implicated the human Ly9 receptor in IL-17 T-cell secretion $(38,39)$. No significant differences were detected in the percentage of IL-17 secreting $\mathrm{CD}^{+} \mathrm{T}$ cells (Figure 6A). On the other hand, our group has previously shown that monoclonal antibodies against Ly9 negatively regulate TCR signaling, thereby inhibiting ERK phosphorylation and IFN- $\gamma$ secretion $(26,40)$. Herein, we investigated the role of Ly9 in IFN- $\gamma$ modulation by activating splenic T cells with antiCD3 and anti-CD28. A significant increase in IFN- $\gamma$ secretion, as well as an increase in the expression of CD40L in $\mathrm{CD} 4^{+} \mathrm{T}$ cells was detected in the absence of Ly9 compared with wt cells (Figures 6B,C). A similar result was obtained when evaluating the expression of the CD25 activation marker (data not shown). In 
Table 1 | Flow cytometry analysis of B- and T-splenic cell subsets from 12-month-old wt and $L_{y} 9^{-1-}$ (BALB/c.129) mice.

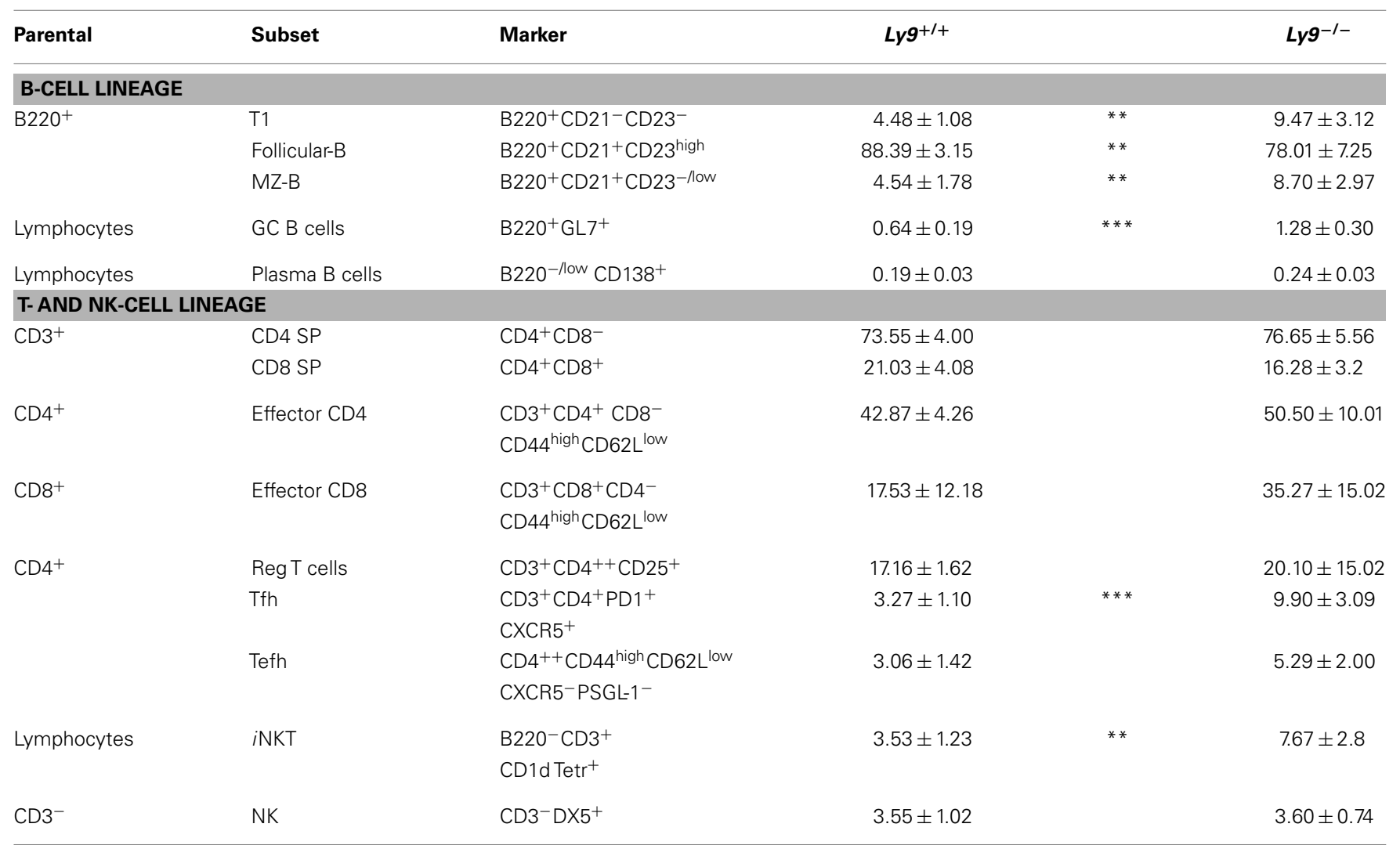

T1, transitional 1 B cells; MZ-B, marginal zone B cells; GC B cells, germinal center B cells; SP, single positive; Reg, regulatory; Tfh, follicular helperT cells; iNKT, invariant natural killer T cells; NK, natural killer; $p$-value significance; ${ }^{* *} p<0.001,{ }^{* * *} p<0.0001$. Results represent the mean \pm SEM of 7 wt and 11 Ly $9^{--}$(BALB/c. 129) mice for each subset analyzed.

addition, PMA/ionomycin activation of splenic cells revealed that Ly9-deficient mice foster $\mathrm{CD} 4^{+} \mathrm{T}, \mathrm{CD} 8^{+} \mathrm{T}$, and $i \mathrm{NKT}$ cells capable of secreting major quantities of IFN- $\gamma$ prior to the development of autoimmunity (Figure 6D). Furthermore, isolated $L y 9$-deficient $\mathrm{CD} 4^{+} \mathrm{T}$ cells consistently showed an increased IFN $-\gamma$ production after PMA/ionomycin activation as compared with wt mice (Figure 6E). In contrast, no significant difference in percentage of IL-4 producing $\mathrm{CD}^{+}{ }^{+} \mathrm{T}$ cells was observed (data not shown). In accordance with these results, 12-month-old $L y 9^{-1-}$ (BALB/c.129) mice exhibited an increased percentage of IFN- $\gamma$ producing $\mathrm{CD}^{+}$ T cells, which correlated with the high ANA titers detected in serum (Figure 6F). Nevertheless, we could not detect IFN- $\gamma$ in the serum of these mice (data not shown).

Thus, in the absence of the Ly9 molecule occurs an increase in peripheral T and $i$ NKT IFN- $\gamma$ secretion, a key cytokine in the pathogenesis of SLE which has been previously shown to trigger the accumulation of pathogenic Tfh and GC B cells (41).

\section{DISCUSSION}

Despite extensive research, the mechanisms by which susceptibility and effector genes initiate and promote autoantibody production and tissue damage remain poorly defined. In the present study, we have shown that $L y 9$ deficiency results in a spontaneous loss of tolerance, reflected principally in the development of autoantibodies, a process which is thought to underlie the initiation of SLE syndrome.

We first found that the absence of the $L y 9$ gene in mice with a B6 and BALB/c background resulted in the development of autoantibodies. The loss of tolerance to nuclear antigens detected in $\mathrm{Lyg}^{-/-}$(B6.129) mice was reminiscent of those previously observed in B6.Sle1b and B6.129Chrlb congenic mouse strains $(6,42)$. We found that $L y 9^{-1-}(B 6.129)$ mice developed autoantibodies as early as 12 weeks of age. In fact, by 9 months of age all mice were autoantibody positive, a pattern similar to that found in SLAMF receptor Slamf1-deficient (B6.129) mice (25). Most SLAMF receptor-deficient mice have been generated by altering those SLAMF genes located in chromosome 1 via the homologous recombination of 129-derived embryogenic stem cells $(25,29,43,44)$. Once the resultant mice are backcrossed onto B6 mice [e.g., Slamf1 ${ }^{-/-}$(B6.129)], the deficient mice are affected by the epistatic interaction that occurs between the 129 gene segment and the B6 genome. Thus, epistatic interactions between 129-derived and B6 genes in $\mathrm{Ly}^{-/-}$(B6.129) mice greatly contribute to the autoantibody response. Exceptionally, the disruption of the Ly108 gene in congenic mice $\left[\right.$ Ly108 ${ }^{-/-}$(B6.129)] mitigates the generation of autoantibodies, indicating that SLAMF members carry out opposing functions (e.g., Ly108 vs. Ly9). 
Table 2 | Flow cytometry analysis of B- and T-splenic cell subsets from 8- to 12-week-old wt and Ly9-I- (BALB/c.129) mice.

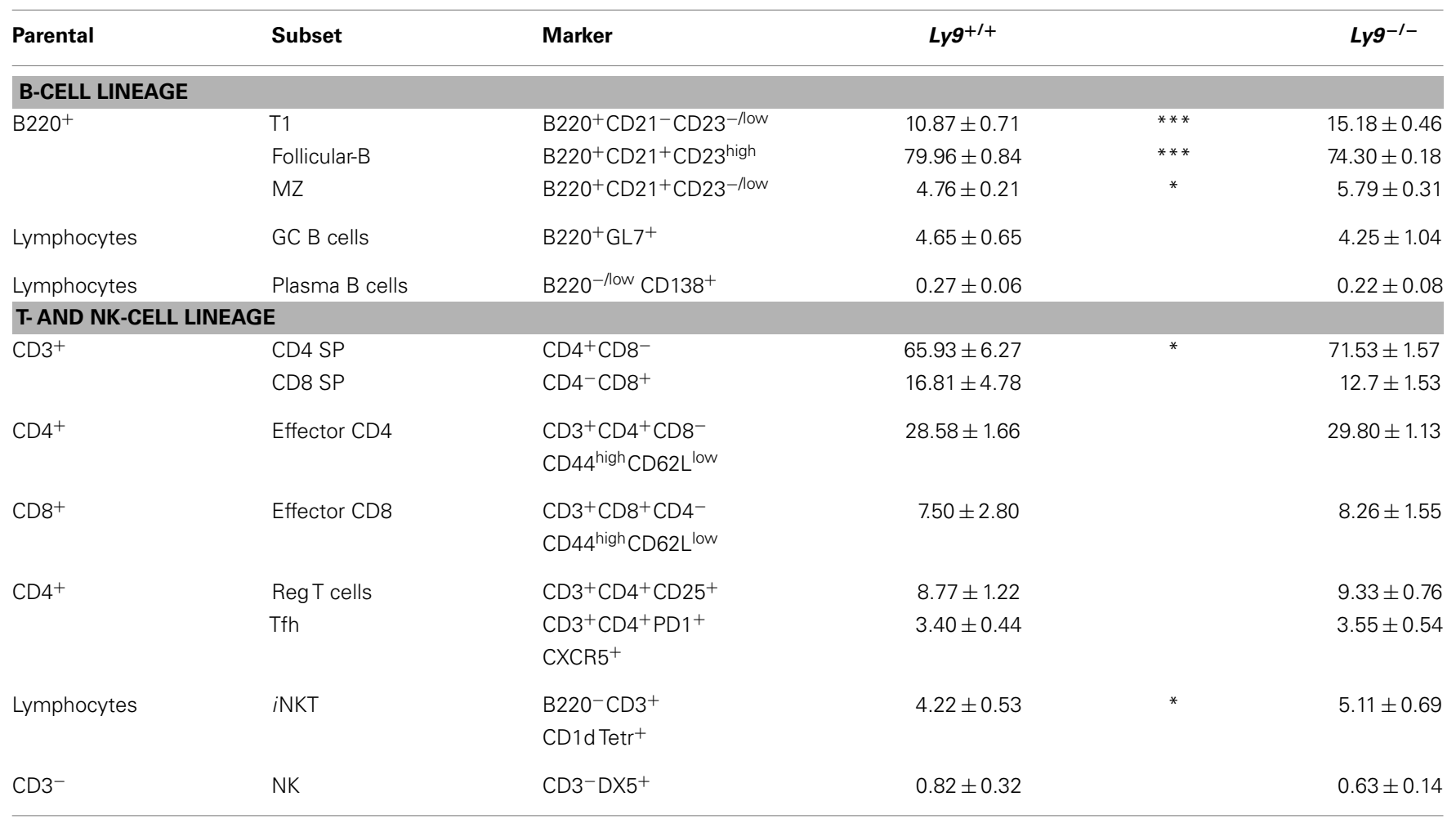

T1, transitional 1 B cells; MZ-B, marginal zone B cells; GC B, germinal center B cells; SP, single positive; Reg, regulatory; Tfh, follicular helper T cells; iNKT, invariant natural killer $T$ cells; NK, natural killer; $p$-value significance; ${ }^{*} p<0.05,{ }^{* * *} p<0.0001$. Results represent the mean $\pm S E M$ of $w t$ and $L y 9^{-1-}(B A L B / c .129)$ mice $(n=5)$ for each subset analyzed.

We next assessed the role of Ly9 in autoimmune disease without the confounding influence of mixed haplotypes by utilizing $L y 9^{-/-}(B A L B / c .129)$ mice. Although autoantibody titers were lower compared to $L y 9^{-/-}$(B6.129) mice, this strain clearly developed an autoimmune response based on the significant increases of ANA, anti-dsDNA, and anti-chromatin antibodies compared to their wt counterparts. By contrast, other SLAMF receptor-deficiencies embedded in the $\mathrm{BALB} / \mathrm{c}$ genome, such as Slamf1 $1^{-/}(B A L B / c .129)$ and Slamf2 ${ }^{-/-}$(BALB/c.129), do not develop any autoimmune response (25), underscoring the role played by Ly 9 as a negative regulator in the pathogenesis of lupus. Consequently, among the various SLAMF receptors, both Ly9 and $2 \mathrm{~B} 4$ rise as unique factors contributing to the reinforcement of tolerance (24).

As a consequence of breaching tolerance, a plethora of disorders can develop a posteriori; e.g., $\mathrm{T}$ and $\mathrm{B}$ cells are reportedly involved in the amplification and perpetuation of the autoimmune response, resulting in inflammation and cytokine dysregulation (45). This proved to be the case in our 12-month-old Ly9-deficient mice in which various $\mathrm{B}$ and $\mathrm{T}$ cells subsets underwent alterations. Notably, the most noteworthy differences in older mice were found in Tfh and GC B cells, two cell types which have been shown to preferentially express the Ly9 receptor (46).

In order to begin to understand why $L y 9$-deficient mice developed spontaneous autoimmunity, we search for any abnormal peripheral B and $\mathrm{T}$ cell development prior to full autoantibody disorder on 8- to 12-week-old Ly9-deficient mice. We observed alterations in the B-cell splenic compartment, with the most prominent expansion displayed by $L y 9$-deficient transitional T1 B cells. Interestingly, SLE patients present increased numbers of T1 cells, although their role in lupus is still ill defined (35). In addition, 8- to 12-week-old Ly9-deficient mice displayed an increase in MZ B cells. Even though many autoreactive antibodies appear to be the product of GC reactions, major evidence begins to reveal that MZ B cells play a key role in homeostasis and tolerance. Notably, the MZ B-cell expansion has been directly implicated in lupus pathogenesis in some murine models (47-50), but not others (51, 52). Autoimmunity mediated by B cell is usually linked to a Bcell hyperresponse which change the B-cell splenic composition. Thus, an increased BCR signal, as shown by mice deficiencies in SHP-1, Fc $\gamma$ RII, CD22, Cbl-b, or overexpressing CD19, leads to a B-cell hyperresponsiveness upon BCR stimulation, change B-cell subsets normal architecture, and culminates in a systemic autoimmune disease (53). Here, we show that there's similar proliferation and survival of $L y 9$-deficient B cells as compared with wt cells, although we can not exclude the abnormal function of particular B-cell subsets in the $L y 9$-deficient mice which could be the subject of future investigations.

Next, we investigated how the absence of Ly9 could possibly contribute to a cytokine imbalance prior to disease onset. Others have shown that the engagement of human naive $\mathrm{CD} 4^{+}$ $\mathrm{T}$ lymphocytes with an anti-human Ly9 monoclonal antibody 


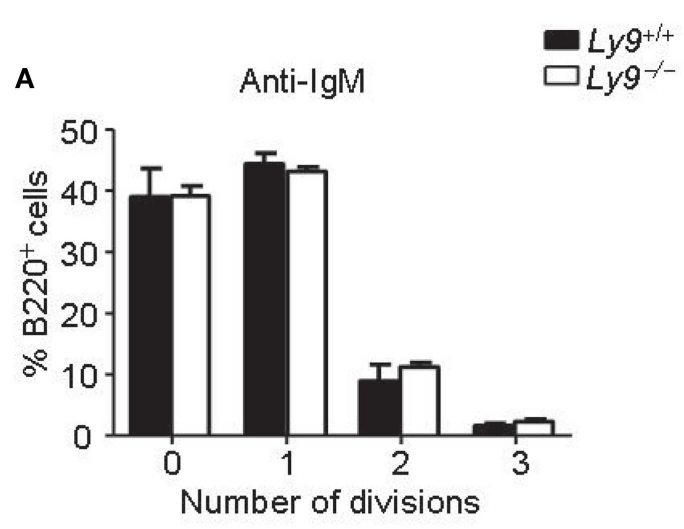

B

Anti-IgM

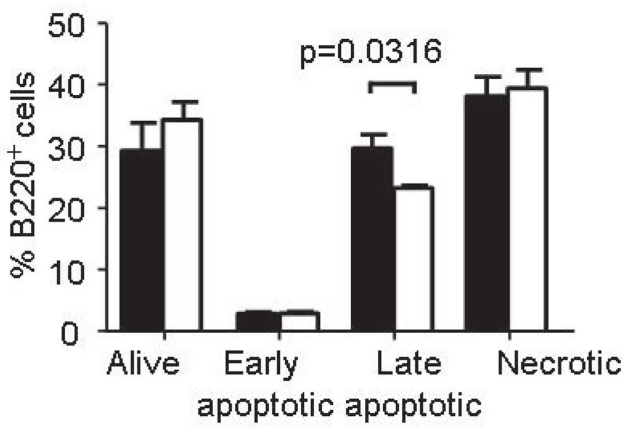

FIGURE 5 | Ly9-deficient B cells displayed similar proliferation and survival than wt cells after IgM stimulation. Splenic cells were obtained from $L y 9^{--}(B A L B / C$. 129) $(n=4)$ or wt $(n=4)$ mice and stimulated with anti-IgM antibody during $72 \mathrm{~h}$. (A) The cells were labeled with CFSE. Flow cytometry analysis of gated B220+ cells was performed. The percentages of $\mathrm{B}$ cells in each division are shown. (B) Apoptosis assay on gated B220+ cells was assessed by flow cytometry. The cells were stained with Live/dead fixable far red and Annexin V eFluor 450. Quantification of the data is presented in a bar diagram (Alive; Live/dead ${ }^{-}$Annexin $\mathrm{V}^{-}$, early apoptotic; Live/dead ${ }^{-}$Annexin $\mathrm{V}^{+}$, late apoptotic; Live/dead ${ }^{+}$Annexin $\mathrm{V}^{+}$, necrotic; Live/dead ${ }^{+}$Annexin $\mathrm{V}^{-}$). (A,B) are representatives of two independent experiments.

under Th17 polarizing conditions results in an increase in IL$17(38,39)$. No alterations in IL-17 producing $\mathrm{T}$ lymphocytes were observed once Ly9-deficient mice splenic cells were activated under Th17 polarizing conditions. Previous reports showed a diminishing IL-4 production and no altered IFN- $\gamma$ secretion by $L y 9$-deficient CD4 T cells (29). In contrast, in the absence of Ly9, we observed an increase in IFN- $\gamma$ producing $\mathrm{T}$ cells with no significant alteration in IL- 4 secretion. Importantly, IFN- $\gamma$ has long been associated with lupus (54). This apparent contradiction could be explained by the influence of epistatic interactions as well as the mice background, since previous studies were performed in $L y 9^{-/-}$with a mixed background $(\mathrm{B} 6 \times 129)$ mice. Recent reports have demonstrated that the overproduction of IFN- $\gamma$ induces an aberrant accumulation of Tfh and GC cells (41).We also found that these subsets underwent expansion in Ly9-deficient mice, when the influence of confounding epistatic interactions was absent. These observations suggest that the Ly9

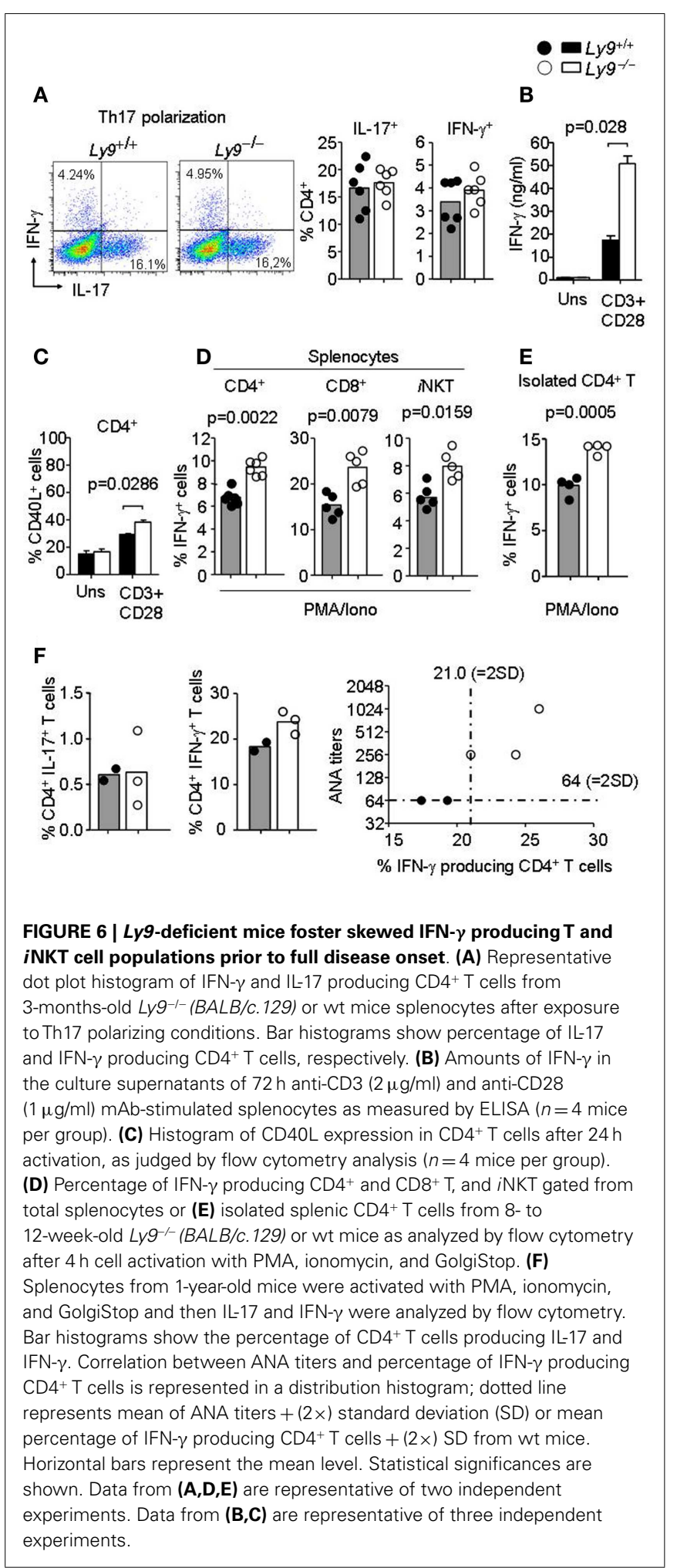

molecule may play an inhibitory role in the expansion of these subsets. In addition, Ly9-deficient mice showed a skewed isotype switching toward $\operatorname{IgG} 2 \mathrm{a} / \mathrm{b}$, an isotype induced by a Th1 response that requires $\mathrm{T}$ cell-stimulated B lymphocytes. Although IgG2a antibodies are the most pathogenic class of immunoglobulin (55, 
56), we did not observe any major kidney pathology. However, a mild increase in IgG-immunocomplex deposits was detected in Ly9-deficient mice, a stage that often precedes full-blown kidney pathology. Thus, an $L y 9$ mutation confers a predisposition to autoantibody generation, but one that may require additional factors (e.g., a viral infection or additional gene alterations) before a full lupus disease pathogenesis becomes evident. In addition, we cannot exclude the influence of $L y 9$-deficient $i$ NKT cells, a population that underwent expansion in 8- to 12 -week-old $L y 9^{-/-}$mice (30), on the observed autoimmune response. Although $i$ NKT cells generally play a tolerogenic role in autoimmunity, some models, and depending on the mouse strain and treatment protocol used, $i$ NKT cell activation exacerbates rather than protects against autoimmunity (57), e.g., the stimulation of $i$ NKT cells triggers a Th1 immune response in adult NZB/W mice, resulting in the exacerbation of systemic autoimmunity (58). Thus, $i$ NKT disease protection is associated with enhanced $\mathrm{Th} 2$ and/or reduced Th1 responses against targeted antigens. A deeper study of Ly9deficient $i$ NKT cell will be needed to determine the specific role of this cell-type in the observed autoimmune phenotype.

In summary, the data presented in this study sheds light on the inhibitory function of the Ly9 cell-surface receptor, suggesting that this molecule is involved in the maintenance of peripheral cell tolerance by serving as a negative regulator of the immune response. Further investigation will be required to elucidate the precise mechanism by which Ly9 confers protection from autoimmunity. Nonetheless, this study demonstrates that Ly9 may not only prove to be a valuable target for the treatment of autoimmunity, but may also help build a more rational road map toward understanding the molecular causes of SLE syndrome.

\section{REFERENCES}

1. Rahman A, Isenberg DA. Systemic lupus erythematosus. $N$ Engl $J$ Med (2008) 358:929-39. doi:10. 1056/NEJMra071297

2. Tsokos GC. Systemic lupus erythematosus. $N$ Engl $J$ Med (2011) 365:2110-21. doi:10.1056/NEJMra1100359

3. Liu Z, Davidson A. Taming lupusa new understanding of pathogenesis is leading to clinical advances. Nat Med (2012) 18:871-82. doi:10. 1038/nm.2752

4. Deng Y, Tsao BP. Genetic susceptibility to systemic lupus erythematosus in the genomic era. Nat Rev Rheumatol (2010) 6:683-92. doi:10.1038/nrrheum. 2010.176

5. Rai E, Wakeland EK. Genetic predisposition to autoimmunity what have we learned? Semin Immunol (2011) 23:67-83. doi:10. 1016/j.smim.2011.01.015

6. Morel L, Blenman KR, Croker BP, Wakeland EK. The major murine systemic lupus erythematosus susceptibility locus, Sle1, is a cluster of functionally related genes. Proc Natl 25.14869

\section{ACKNOWLEDGMENTS}

Jose de Salort performed most of the experiments and analyzed the data; Marta Cuenca performed the B-cell functional experiments; Pablo Engel and Xavier Romero designed the experiments and supervised the study; Jose de Salort, Pablo Engel, and Xavier Romero wrote the manuscript; Cox Terhorst provided input into the conceptual development of the experiments and edited the manuscript. We thank Adriana Lázaro for technical assistance. We also thank the NIH Tetramer Core Facility for providing R-PE labeled murine CD1d tetramer pre-loaded with PBS57. This work was supported by the Ministerio de Educación y Ciencia through Grants SAF 2009-07071/SAF 2012-39536 (to Pablo Engel) and by a grant from the NIH (2P01AI65687-06A1 to Pablo Engel and Cox Terhorst). Jose de Salort was supported by Ayuda Personal Investigador en Formación (APIF), a grant from the Universitat de Barcelona. Marta Cuenca was supported by Ministerio de Educación, Cultura y Deporte (AP2010-1754). Xavier Romero was supported by Beatriu de Pinos (2010 BP-B).

\section{SUPPLEMENTARY MATERIAL}

The Supplementary Material for this article can be found online at http://www.frontiersin.org/Inflammation/10.3389/fimmu.2013. 00225/abstract

Figure S1 | Splenic T1 and MZ cells are expanded in $L y 9^{-/-}(B A L B / c .129)$ mice. (A) Spleen lymphocytes from 8- to 12-week-old wt $(n=5)$ and Ly $9^{-/-}(B A L B / C .129)$ mice $(n=5)$ were stained using CD23, CD21, and IgM. (A) Representative dot plots from wt and $L y 9^{--}$splenic cells. The gating strategy to characterize transitional and marginal zone (MZ) B cells is shown. (B) Quantitative analysis of the CD23- percentage of $\mathrm{MZ}$ and Transitional 1 (T1) B cells as well as (C) MZ- and T1-B cells cellularity per spleen are shown. SEM and statistical significances are shown.

706-14. doi:10.1016/j.coi.2010.10 014 doi:10.1073/pnas.98.4.1787

7. Tsao BP, Cantor RM, Kalunian KC, Chen CJ, Badsha H, Singh R, et al. Evidence for linkage of a candidate chromosome 1 region to human systemic lupus erythematosus. J Clin Invest (1997) 99:725-31. doi:10.1172/JCI119217

8. Moser KL, Neas BR, Salmon JE, Yu H, Gray-McGuire C, Asundi $\mathrm{N}$, et al. Genome scan of human systemic lupus erythematosus: evidence for linkage on chromosome 1q in African-American pedigrees. Proc Natl Acad Sci U S A (1998) 95:14869-74. doi:10.1073/pnas.95.

9. Wandstrat AE, Nguyen C, Limaye N, Chan AY, Subramanian S, Tian $\mathrm{XH}$, et al. Association of extensive polymorphisms in the SLAM/CD2 gene cluster with murine lupus. Immunity (2004) 21:769-80. doi:10.1016/j.immuni.2004.10.009

10. Wang A, Batteux F, Wakeland EK. The role of SLAM/CD2 polymorphisms in systemic autoimmunity. Curr Opin Immunol (2010) 22:
11. Detre C, Keszei M, Romero X, Tsokos GC, Terhorst C. SLAM family receptors and the SLAMassociated protein (SAP) modulate $\mathrm{T}$ cell functions. Semin Immunopathol (2010) 32:157-71. doi:10.1007/s00281-009-0193-0

12. Engel P, Eck MJ, Terhorst C. The SAP and SLAM families in immune responses and $\mathrm{X}$-linked lymphoproliferative disease. Nat Rev Immunol (2003) 3:813-21. doi: $10.1038 /$ nri1202

13. Veillette A. Immune regulation by SLAM family receptors and SAP-related adaptors. Nat Rev Immunol (2006) 6:56-66. doi:10. 1038/nril761

14. Calpe S, Wang N, Romero X, Berger SB, Lanyi A, Engel $P$, et al. The SLAM and SAP gene families control innate and adaptive immune responses. Adv Immunol (2008) 97:177-250. doi:10.1016/ S0065-2776(08)00004-7

15. Cannons JL, Tangye SG, Schwartzberg PL. SLAM family receptors and SAP adaptors in immunity. Annu Rev Immunol (2011) 29:665-705. doi:10.1146/ annurev-immunol-030409-101302

16. Qi H, Cannons JL, Klauschen F, Schwartzberg PL, Germain RN. SAP-controlled T-B cell interactions underlie germinal centre formation. Nature (2008) 455:764-9. doi:10.1038/ nature 07345

17. Cannons JL, Qi H, Lu KT, Dutta M, Gomez-Rodriguez J, Cheng J. Optimal germinal center responses require a multistage $\mathrm{T}$ Cell: $\mathrm{B}$ cell adhesion process involving integrins, SLAM-associated protein, and CD84. Immunity (2010) 32:253-65. doi:10.1016/j.immuni. 2010.01.010

18. Ma CS, Deenick EK, Batten M, Tangye SG. The origins, function, and regulation of $\mathrm{T}$ follicular helper cells. J Exp Med (2012) 209:124153. doi:10.1084/jem.20120994

19. Hron JD, Caplan L, Gerth AJ, Schwartzberg PL, Peng SL. SH2D1A regulates $\mathrm{T}$-dependent humoral autoimmunity. $J$ Exp Med (2004) 200:261-6. doi:10.1084/jem.20040526 
20. Chan AY, Westcott JM, Mooney JM, Wakeland EK, Schatzle JD. The role of SAP and the SLAM family in autoimmunity. Curr Opin Immunol (2006) 18:656-64. doi:10.1016/j.coi. 2006.09.010

21. Linterman MA, Rigby RJ, Wong RK, Yu D, Brink R, Cannons JL, et al. Follicular helper $\mathrm{T}$ cells are required for systemic autoimmunity. J Exp Med (2009) 206:561-76. doi:10.1084/jem.20081886

22. Linterman MA, Liston A, Vinuesa CG. T-follicular helper cell differentiation and the co-option of this pathway by non-helper cells. Immunol Rev (2012) 247:14359. doi:10.1111/j.1600-065X.2012. 01121.x

23. Kumar KR, Li L, Yan M, Bhaskarabhatla M, Mobley AB, Nguyen $C$, et al. Regulation of $B$ cell tolerance by the lupus susceptibility gene Ly108. Science (2006) 312:1665-9. doi:10. 1126/science. 1125893

24. Brown DR, Calpe S, Keszei M, Wang N, McArdel S, Terhorst C, et al. Cutting edge: an NK cellindependent role for Slamf4 in controlling humoral autoimmunity. $J$ Immunol (2011) 187:21-5. doi:10. 4049/jimmunol.1100510

25. Keszei M, Latchman YE, Vanguri VK, Brown DR, Detre C, Morra $\mathrm{M}$, et al. Auto-antibody production and glomerulonephritis in congenic Slamf1-/- and Slamf2-/[B6.129] but not in Slamf1-/- and Slamf2-/- [BALB/c.129] mice. Int Immunol (2011) 23:149-58. doi:10. 1093/intimm/dxq465

26. Sintes J, Vidal-Laliena M, Romero $\mathrm{X}$, Tovar V, Engel P. Characterization of mouse CD229 (Ly9), a leukocyte cell surface molecule of the CD150 (SLAM) family. Tissue Antigens (2007) 70:355-62. doi:10.1111/ j.1399-0039.2007.00909.x

27. Sayos J, Martin M, Chen A, Simarro M, Howie D, Morra M, et al. Cell surface receptors Ly-9 and CD84 recruit the X-linked lymphoproliferative disease gene product SAP. Blood (2001) 97:3867-74. doi:10. 1182/blood.V97.12.3867

28. Romero X, Zapater N, Calvo M, Kalko SG, de la Fuente MA, Tovar $\mathrm{V}$, et al. CD229 (Ly9) lymphocyte cell surface receptor interacts homophilically through its $\mathrm{N}$ terminal domain and relocalizes to the immunological synapse. $J$ Immunol (2005) 174:7033-42.

29. Graham DB, Bell MP, McCausland MM, Huntoon CJ, van Deursen J, Faubion WA, et al. Ly9 (CD229)deficient mice exhibit $\mathrm{T}$ cell defects yet do not share several phenotypic characteristics associated with SLAM- and SAP-deficient mice. $J$ Immunol (2006) 176:291-300.

30. Sintes J, Cuenca M, Romero X, Bastos R, Terhorst C, Angulo A, et al. Cutting edge: Ly9 (CD229), a SLAM family receptor, negatively regulates the development of thymic innate memory-like CD8+ $\mathrm{T}$ and invariant NKT cells. $J$ Immunol (2013) 190:21-6. doi:10. 4049/jimmunol.1202435

31. Reeves WH, Lee PY, Weinstein JS, Satoh M, Lu L. Induction of autoimmunity by pristane and other naturally occurring hydrocarbons. Trends Immunol (2009) 30(9):45564. doi:10.1016/j.it.2009.06.003

32. Mohan C, Morel L, Yang $P$, Watanabe H, Croker B, Gilkeson $G$, et al. Genetic dissection of lupus pathogenesis: a recipe for nephrophilic autoantibodies. J Clin Invest (1999) 103(12):1685-95. doi: 10.1172/JCI5827

33. Morel L, Croker BP, Blenman KR, Mohan C, Huang G, Gilkeson G, et al. Genetic reconstitution of systemic lupus erythematosus immunopathology with polycongenic murine strains. Proc Natl Acad Sci U S A (2000) 97:6670-5. doi:10.1073/pnas.97.12.6670

34. Dorner T, Giesecke C, Lipsky PE. Mechanisms of B cell autoimmunity in SLE. Arthritis Res Ther (2011) 13:243. doi:10.1186/ar3433

35. Vossenkamper A, Lutalo PM, Spencer J. Translational minireview series on B cell subsets in disease. Transitional B cells in systemic lupus erythematosus and Sjogren's syndrome: clinical implications and effects of B cell-targeted therapies. Clin Exp Immunol (2012) 167:7-14. doi:10.1111/j.1365-2249. 2011.04460.x

36. Lian ZX, Kita H, Okada T, Hsu T, Shultz LD, Dorshkind K, et al. Increased frequency of Pre-Pro $B$ cells in the bone marrow of New Zealand Black (NZB) mice: implications for a developmental block in B cell differentiation. Dev Immunol (2002) 9:35-45. doi:10. 1080/1044667021000003961

37. Carsetti R. Characterization of Bcell maturation in the peripheral immune system. Methods Mol Biol (2004) 271:25-35.

38. Chatterjee M, Hedrich CM, Rauen $\mathrm{T}$, Ioannidis C, Terhorst C, Tsokos GC. CD3-T cell receptor co-stimulation through SLAMF3 and SLAMF6 receptors enhances RORgammat recruitment to the IL17A promoter in human $\mathrm{T}$ lymphocytes. $J$ Biol
Chem (2012) 287:38168-77. doi:10.1074/jbc.M112.415067

39. Chatterjee M, Rauen T, Kis-Toth K, Kyttaris VC, Hedrich CM, Terhorst $\mathrm{C}$, et al. Increased expression of SLAM receptors SLAMF3 and SLAMF6 in systemic lupus erythematosus $\mathrm{T}$ lymphocytes promotes Th17 differentiation. J Immunol (2012) 188:1206-12. doi:10.4049/ jimmunol.1102773

40. Martin M, Del Valle JM, Saborit I, Engel P. Identification of Grb2 as a novel binding partner of the signaling lymphocytic activation molecule-associated protein binding receptor CD229. J Immunol (2005) 174:5977-86.

41. Lee SK, Silva DG, Martin JL, Pratama A, Hu X, Chang PP, et al. Interferon-gamma excess leads to pathogenic accumulation of follicular helper $\mathrm{T}$ cells and germinal centers. Immunity (2012) 37:880-92. doi:10.1016/j.immuni. 2012.10.010

42. Carlucci F, Cortes-Hernandez J, Fossati-Jimack L, Bygrave AE, Walport MJ, Vyse TJ, et al. Genetic dissection of spontaneous autoimmunity driven by 129 -derived chromosome 1 loci when expressed on C57BL/6 mice. J Immunol (2007) 178:2352-60

43. Cruz-Munoz ME, Dong Z, Shi X, Zhang S, Veillette A. Influence of CRACC, a SLAM family receptor coupled to the adaptor EAT-2, on natural killer cell function. Nat Immunol (2009) 10:297-305. doi: 10.1038/ni.1693

44. Keszei M, Detre C, Rietdijk ST, Munoz P, Romero X, Berger SB, et al. A novel isoform of the Ly108 gene ameliorates murine lupus. Exp Med (2011) 208:811-22. doi:10. 1084/jem.20101653

45. Ronnblom L, Elkon KB. Cytokines as therapeutic targets in SLE. Nat Rev Rheumatol (2010) 6:339-47. doi:10.1038/nrrheum.2010.64

46. Chtanova T, Tangye SG, Newton R, Frank N, Hodge MR, Rolph MS, et al. $\mathrm{T}$ follicular helper cells express a distinctive transcriptional profile, reflecting their role as non-Th1/Th2 effector cells that provide help for B cells. J Immunol (2004) 173:68-78.

47. Zhou Z, Niu H, Zheng Y, And Morel L. Autoreactive marginal zone B cells enter the follicles and interact with CD4+ $\mathrm{T}$ cells in the lupusprone mice. BMC Immunol (2011) 12:7. doi:10.1186/1471-2172-12-7

48. Grimaldi CM, Michael DJ, Diamond B. Cutting edge: expansion and activation of a population of autoreactive marginal zone $\mathrm{B}$ cells in a model of estrogen-induced lupus. J Immunol (2001) 167:1886-90.

49. Mackay F, Woodcock SA, Lawton $\mathrm{P}$, Ambrose $\mathrm{C}$, Baetscher $\mathrm{M}$, Schneider $\mathrm{P}$, et al. Mice transgenic for BAFF develop lymphocytic disorders along with autoimmune manifestations. $J$ Exp Med (1999) 190:1697-710. doi:10.1084/ jem.190.11.1697

50. Wither JE, Loh C, Lajoie G, Heinrichs S, Cai YC, Bonventi G, et al. Colocalization of expansion of the splenic marginal zone population with abnormal B cell activation and autoantibody production in B6 mice with an introgressed New Zealand Black chromosome 13 interval. J Immunol (2005) 175:4309-19.

51. Atencio S, Amano H, Izui S, Kotzin BL. Separation of the New Zealand Black genetic contribution to lupus from New Zealand Black determined expansions of marginal zone B and Bla cells. J Immunol (2004) 172:4159-66.

52. Amano H, Amano E, Moll T, Marinkovic D, Ibnou-Zekri N, Martinez-Soria E, et al. The Yaa mutation promoting murine lupus causes defective development of marginal zone B cells. J Immunol (2003) 170:2293-301.

53. Pugh-Bernard AE, Cambier JC. B cell receptor signaling in human systemic lupus erythematosus. Curr Opin Rheumatol (2006) 18(5):4515. doi:10.1097/01.bor.0000240353. 99808.5f

54. Theofilopoulos AN, Koundouris S, Kono DH, Lawson BR. The role of IFN-gamma in systemic lupus erythematosus: a challenge to the Th1/Th2 paradigm in autoimmunity. Arthritis Res (2001) 3:136-41. doi:10.1186/ar290

55. Snapper CM, Paul WE. Interferongamma and $B$ cell stimulatory factor-1 reciprocally regulate Ig isotype production. Science (1987) 236:944-7. doi:10.1126/science.3107127

56. Baudino L, Zeredoda SS, Nakata M, Izui S. Molecular and cellular basis for pathogenicity of autoantibodies: lessons from murine monoclonal autoantibodies. Springer Semin Immunopathol (2006) 28: 175-84. doi:10.1007/s00281-0060037-0

57. Van Kaer L, Parekh VV, Wu L. Invariant natural killer $\mathrm{T}$ cells as sensors and mangers of inflammation. Trends Immunol (2013) 34:50-8. doi:10.1016/j.it.2012.08.009

58. Zeng D, Liu Y, Sidobre S, Kronenberg M, Strober S. Activation of 
natural killer $\mathrm{T}$ cells in NZB/W mice induces Thl-type immune responses exacerbating lupus. J Clin Invest (2003) 112:1211-22. doi:10. 1172/JCI200317165

Conflict of Interest Statement: The authors declare that the research was conducted in the absence of any commercial or financial relationships that could be construed as a potential conflict of interest.

Received: 15 May 2013; paper pending published: 05 June 2013; accepted: 18 July 2013; published online: 31 July 2013.

Citation: de Salort J, Cuenca M, Terhorst C, Engel P and Romero X (2013) Ly9 (CD229) cell-surface receptor is crucial for the development of spontaneous autoantibody production to nuclear antigens. Front. Immunol. 4:225. doi: 10.3389/fimmu.2013.00225

This article was submitted to Frontiers in Inflammation, a specialty of Frontiers in Immunology.

Copyright $\odot 2013$ de Salort, Cuenca, Terhorst, Engel and Romero. This is an openaccess article distributed under the terms of the Creative Commons Attribution License (CC BY). The use, distribution or reproduction in other forums is permitted, provided the original author (s) or licensor are credited and that the original publication in this journal is cited, in accordance with accepted academic practice. No use, distribution or reproduction is permitted which does not comply with these terms. 